\title{
Formación de investigadores educativos en Chiapas: realidades y falacias
}

\author{
Training of Educational Researchers in Chiapas: \\ Realities and fallacies
}

Luis Alan Acuña Gamboa*

\section{RESUMEN}

El presente artículo tiene la intención de posicionar la Formación de Investigadores Educativos (FIE) como eje principal para la realización de Investigación Educativa (IE) en Chiapas, puesto que ésta es una de las líneas con menor producción de conocimiento en el campo educativo, lo cual se comprueba con la revisión actual de su estado del arte (2003-2016). Con base en las categorías "prestigio educativo" $y$ "oferta de doctorados formadores en IE", se analizaron los procesos de cuatro universidades de la entidad (tres privadas y una pública) sobre los que se aleccionan a los futuros investigadores en educación, así como la postura que sus egresados han construido de dichos procesos. Para ello se contó con una muestra voluntaria de 40 estudiantes y 20 egresados $y$, con base en los resultados obtenidos, se puede concluir que la oferta privada de posgrados responde más a los modelos económicos globales (mercantilización educativa) que al interés por desarrollar capital humano de alto nivel como lo define el discurso político oficial mexicano; mientras que, para el sector público, se preveía un 2017 lleno de recortes presupuestales que tienen como objetivo descentralizar estos niveles formativos al pecunio de los interesados.

Palabras clave: investigación educativa, educación superior, formación de investigadores, análisis comparativo

\section{ABSTRACT}

This article has the intention, in the first place, of positioning educational researchers' training (ERT) as the main axis for Educational Research (ER) in Chiapas, given the first is one of the lines with less knowledge production in the field of education as proves the revision of the state of the art (2003-2016). Based on the categories "educational prestige" and "supply of doctoral trainers in ER", the processes of four universities in Chiapas that offer training in educational research (three private and one public) were analyzed, as well as the stance of their graduates on those processes. To this end, an analysis of a voluntary sample of 40 students and 20 graduates derived the conclusion that the private supply of graduate studies responds more to the global economic models (commodification of education) than to the interest in developing high level human capital as defined by the Mexican official political discourse; whereas, for the public sector, it was foreseen a 2017 full of budget constraints that aim to decentralize these training levels to the detriment of the interested.

Key words: educational research, higher education, researchers education, comparative analysis

\footnotetext{
‘Doctorado en Estudios Regionales. Universidad Autónoma de Chiapas; acugam2319@ gmail.com
} 


\section{INTRODUCCIÓN}

Desde finales del siglo XX y principios del XXI, la educación se ha estructurado y alineado cada vez más con las dinámicas e intereses económicos globales, al grado de supeditar sus objetivos a las visiones, propósitos y demandas de la estructura neoliberal y capitalista que rige al planeta entero. Como prueba de ello, se pueden analizar los acuerdos del Foro Mundial sobre la Educación 2015 (UNESCO, 2015), en los cuales quedaron representadas las voces empresariales, economicistas y tecnológicas que definen el deber ser de la calidad educativa de cara al 2030; sin embargo, se evidenció la exigua participación de los actores más importantes en los procesos educativos mundiales; es decir, docentes, investigadores e intelectuales del campo.

Ante tal situación, las tendencias educativas a futuro continuarán rigiéndose por los principios hegemónicos de la economía mundial y no por las necesidades educativas regionales, situación que ha llevado a la comunidad científica a reflexionar sobre el gran apagón pedagógico global (Bonilla-Molina, 2016; Colectivo de actores clave en educación, s. f.), que está en marcha a través de estas evasiones contra la educación, y vaticinan cambios drásticos en la manera de entenderla, así como la regresiva evolución en las formas en que ésta llegará a la sociedad.

A pesar de esto, en México se erige un discurso político sobre la educación de calidad que enarbola la necesidad de formar capital humano con altas capacidades como medio para el desarrollo del país. Aunque en otros espacios se ha demostrado que la educación, específicamente en términos de calidad, responde más a la alineación estructurada del discurso educativo nacional con aquellas visiones de las altas esferas de poder simbólico y económico global (Acuña Gamboa y Pons Bonals, 2016), el Gobierno Federal a través del Consejo Nacional de Ciencia y Tecnología (Conacyt), busca desarrollar e incrementar la producción científica y tecnológica con apoyos monetarios a estudiantes de posgrado (especialidad, maestría y doctorado), así como a los científicos y tecnólogos registrados en el Sistema Nacional de Investigadores (SNI) quienes fungen como medida preventiva, si no correctiva, de la realidad social y educativa del país. 
Sin embargo, la investigación en educación -con énfasis en la formación de investigadores educativos- es una de las áreas que menos apoyos gubernamentales percibe año con año, bien sea por considerársele de poca importancia, bien por el exiguo número de investigadores dentro del campo. Por ello, es necesario realizar investigaciones que den cuenta del diseńo e implementación de las políticas públicas en educación superior que se están accionando para alcanzar dichos objetivos.

De tal manera, este artículo tiene como propósito exponer las realidades y falacias existentes entre el discurso político relacionado con la formación de investigadores educativos en México, y la situación que se vive actualmente en el estado de Chiapas al respecto; aunado a ello, el trabajo invita a los especialistas en educación a fijar sus objetos de estudio en la temática aquí abordada. Con base en estos objetivos, el documento se divide en cinco apartados: en el primero se presentan las fases de la investigación y la metodología que se siguió en cada una de éstas; en el segundo, se discute la situación político-formativa mexicana en relación con la formación de investigadores en educación, priorizando los problemas regionales que aquejan a este campo.

En el tercero se realiza un recuento del estado del arte (2003-2016) de la temática en Chiapas, tras lo cual es posible aseverar que se ha investigado poco al respecto; en el cuarto se exponen los hallazgos más importantes del trabajo investigativo para que, por último, se analicen y discutan las conclusiones, al término de la sistematización y la reflexión de los datos presentados.

\section{APARATO METODOLÓGICO DE LA INVESTIGACIÓN}

El trabajo responde a la necesidad de realizar un análisis comparado entre los procesos formativos de investigadores en educación de los sectores público y privado del estado de Chiapas. Para ello, la investigación se realizó en dos fases de igual importancia durante las pesquisas; en la primera, se jerarquizaron y analizaron los documentos rectores nacionales donde se sustenta la necesidad de formar capital humano de alto nivel y calidad (Gobierno de la República, 2013) dentro del campo de la investigación y pro- 
ducción de conocimiento científico para el desarrollo económico y tecnológico del país y, en un segundo momento, se realizó una revisión del estado del arte -en términos de producción científica- sobre la Formación de Investigadores Educativos en Chiapas. Ambas actividades tomaron como base el análisis de textos desde un enfoque informal, el cual, de acuerdo con Peräkylä (2015), resulta de suma utilidad en investigaciones en las que el análisis textual cualitativo es complementario de otras técnicas.

En la segunda fase, se jerarquizaron las Instituciones de Educación Superior (IES) con base en los siguientes parámetros: 1) que por su infraestructura, calidad docente y población estudiantil atendida sean reconocidas por lo menos a nivel estatal; 2) que cuenten con posgrados (específicamente doctorados) cuyo perfil de egreso esté relacionado con la formación de investigadores educativos, y 3) que cuenten con estudiantes en el último periodo de su formación, así como, por lo menos, con dos generaciones de egresados.

106 Producto de esta actividad se seleccionaron, del total de IES en la entidad, las cuatro universidades que cumplieron con los parámetros antes señalados, distribuyéndose de la siguiente manera: por parte del sector público, la línea de investigación Educación, Actores y Procesos Enseñanza Aprendizaje (ahora nombrada Problemas Educativos Regionales) del Doctorado en Estudios Regionales de la Universidad Autónoma de Chiapas (UNACH) y, por parte del sector privado, los Doctorados en Educación de la Universidad del Sur (US), la Universidad Valle del Grijalva (UVG) y del Instituto de Estudios Superiores de Chiapas (IESCH). Asimismo, se recuperaron las visiones, experiencias y puntos de encuentro y desencuentro de los procesos en investigación educativa a los que estudiantes y egresados de estas IES que fueron formados de cara al cumplimiento de los objetivos institucional, estatal y nacional que buscan el desarrollo del campo.

La muestra estuvo conformada por 40 estudiantes y 20 egresados (diez y cinco por IES, respectivamente), quienes fueron elegidos de manera intencional con un criterio de conveniencia (Flick, 2012), buscando que, en todo momento, representara, por lo menos, $50 \%$ de los estudiantes de último cuatrimestre, pentamestre o semestre en cada plan de estudio, así como $25 \%$ de 
los egresados de cada doctorado. Dicha muestra fue predeterminada y se constituyó mediante el consentimiento en participar de forma voluntaria en la investigación, acordándose la salvaguarda del anonimato de los informantes durante todas las actividades.

El trabajo se realizó con base en el método de estudio colectivo de casos de carácter inductivo-explicativo (Stake, 1999; Álvarez Álvarez y San Fabián Maroto, 2012; Jiménez Chaves, 2012), el cual permitió analizar y comprender, a profundidad, las características específicas del capital humano formado en las cuatro universidades seleccionadas (casos); esto posibilitó respuestas a las preguntas de investigación: ¿cómo se realizan los procesos de formación de investigadores educativos en los sectores público y privado en el estado de Chiapas? y, ¿por qué, a pesar del gran incremento de IES ofertantes de posgrados formadores en investigación educativa en la entidad, la producción de conocimiento en el campo es aquí notablemente exigua?

El levantamiento de la información se llevó a cabo en dos etapas; en un primer momento, se aplicó a toda la muestra el Instrumento de Formación de Investigadores Educativos (IFIE), el cual consta de 15 preguntas (abiertas y de opción múltiple) sobre el ser y el quehacer investigativo, entendido en términos de producción académica, tiempo empleado en la investigación y conocimiento general en investigación educativa (sustentos teóricos y epistemológicos de sus investigaciones, enfoques, paradigmas, métodos, técnicas e instrumentos de investigación, etc.); de esta manera, el IFIE arrojó datos importantes que permitieron caracterizar el perfil de los estudiantes y egresados de las IES seleccionadas. En la segunda etapa, se realizaron entrevistas semiestructuradas a $20 \%$ de los participantes (14 estudiantes y seis egresados) con la finalidad de obtener sus percepciones acerca de la calidad del posgrado en el que se forman como investigadores educativos, así como la postura que asumen de cara a los retos que genera, dentro del ámbito laboral, su profesión investigativa. 


\section{La investigación educativa en México: recuento de un problema político-formativo}

La generación y el desarrollo científico y tecnológico se ha posicionado, a lo largo de la historia del Sistema Educativo Nacional (SEN), como uno de los principales ejes de planeación, hechura e implementación de políticas públicas en México, como respuesta al anhelado despegue económico y social que se ha pretendido realizar por y para el país, por lo menos en el plano discursivo (ver Gobierno de la República, 1989; 1995; 2001 y 2007). Ante esta férrea empresa, cuya génesis data de la década de los ochenta; la actual administración federal, ha fijado nuevamente dentro de sus documentos rectores la "formación y fortalecimiento del capital humano de alto nivel" (Gobierno de la República, 2013, p. 128) como la vía para alcanzar el progreso económico y social que México necesita, bien sea a través del fomento de "la investigación científica y tecnológica en las instituciones de educación superior y centros públicos de investigación [bien por] la generación y aplicación del conocimiento" (SEP, 2013, p. 13) para desentrañar los elementos innovadores que transformarían a México en un país de primer nivel.

Para concretar esto, el actual gobierno mexicano ha considerado que el desarrollo económico del país esté íntimamente relacionado con la capacidad que éste tenga para lograr la apropiación social del conocimiento; por ende, en el Plan Nacional de Desarrollo (PND) 2013-2018 se presenta la necesidad de "basar nuestro futuro en el aprovechamiento intensivo de nuestra capacidad intelectual" (Gobierno de la República, 2013, p. 59) como medio e instrumento para alcanzar dicha apropiación. Sin embargo, uno de los diagnósticos presentados en el PND 2013-2018 demuestra que México se encuentra entre los países que menos contribuyen a la producción de conocimiento, por debajo de $1 \%$ del total alcanzado a nivel mundial, índice en el cual la formación de posgrado -en términos específicos de estudios doctorales concluidos- representa $0.0029 \%$ por cada millón de habitantes (Gobierno de la República, 2013; Secretaría de Educación Pública, 2013); es decir, menos de 30 doctores repartidos en las diferentes líneas de investigación desarrolladas en el 
país. Con la intención de contrarrestar dicha problemática, tanto en el PND como en el Programa Sectorial de Educación (PSE) 2013-2018 se plasman los objetivos, estrategias y líneas de acción por las que el SEN debe transitar en aras de mejorar la calidad educativa que se oferta a nivel nacional.

En este sentido, uno de los objetivos de este proyecto de país se relaciona directamente con el desarrollo de la investigación en México, puesto que busca el progreso económico y social a través del desarrollo científico, tecnológico e innovador en la sociedad. De esta manera, el objetivo 3.5 del PND 2013-2018 sentencia que al "hacer del desarrollo científico, tecnológico y la innovación [los] pilares para el progreso económico y social sostenible" (Gobierno de la República, 2013, p. 128) se medrará la situación por la que viene atravesando la sociedad mexicana. A manera de epítome, en el cuadro 1 se exponen las principales estrategias y líneas de acción que el PND y el PSE actuales han accionado para alcanzar el objetivo previsto desde su diseño, con especial énfasis en aquellas que se relacionan directamente con la formación de investigadores.

Como se puede observar, la constante en estas estrategias y líneas de acción es la formación de capital humano de alto nivel para que atienda las necesidades del sector productivo nacional; en palabras del presidente de México, con esto se debe "aspirar a que la competitividad de nuestra mano de obra esté basada preponderantemente en su calidad" (Gobierno de la República, 2013, p. 59). La institución encargada de velar porque esto se concrete de forma óptima es, principalmente, el Consejo Nacional de Ciencia y Tecnología (Conacyt), organismo creado en diciembre de 1970 con la encomienda de "consolidar un Sistema Nacional de Ciencia y Tecnología que responda a las demandas prioritarias del país [incrementando] la capacidad científica y tecnológica” (Conacyt, 2014a, s.p.). 


\section{CUADRO 1. Estrategias y líneas de acción de las políticas de formación de investigadores en México}

\begin{tabular}{|c|c|}
\hline Plan nacional de desarrollo 2013-2018 & Programa sectorial de educación 2013-2018 \\
\hline \multicolumn{2}{|c|}{ Estrategia: Contribuir a la formación y fortalecimiento del capital humano de alto nivel. } \\
\hline $\begin{array}{l}\text { Líneas de acción: } \\
\text { Incrementar el número de becas de posgrado mediante la } \\
\text { consolidación de los programas vigentes y la incorporación } \\
\text { de nuevas modalidades educativas. } \\
\text { Fortalecer el Sistema Nacional de Investigadores (SNI), } \\
\text { incrementando el número de científicos y tecnólogos } \\
\text { incorporados. } \\
\text { Fomentar la calidad de la formación impartida por los } \\
\text { programas de posgrado, mediante su acreditación en el } \\
\text { Programa Nacional de Posgrados de Calidad (PNPC). }\end{array}$ & $\begin{array}{l}\text { Líneas de acción: } \\
\text { Trabajar coordinadamente con el Consejo Nacional } \\
\text { de Ciencia y Tecnología (Conacyt) para incrementar la } \\
\text { oferta en el PNPC. } \\
\text { Orientar y apoyar a las instituciones de educación } \\
\text { superior para facilitar la incorporación de sus } \\
\text { programas de posgrado al PNPC. } \\
\text { Incrementar el número y el nivel de los investigadores } \\
\text { de las instituciones de educación superior en el SNI. } \\
\text { Alentar la participación de estudiantes en actividades } \\
\text { de investigación. }\end{array}$ \\
\hline \multicolumn{2}{|c|}{$\begin{array}{l}\text { Estrategia: Fortalecer la capacidad analítica y creativa de los mexicanos } \\
\text { con una visión moderna de la ciencia y la tecnología. }\end{array}$} \\
\hline $\begin{array}{l}\text { Líneas de acción: } \\
\text { Promover el desarrollo emprendedor de las instituciones } \\
\text { de educación superior y los centros de investigación, con el } \\
\text { fin de fomentar la innovación tecnológica y el autoempleo } \\
\text { entre los jóvenes. } \\
\text { Enfocar el esfuerzo educativo y de capacitación para el } \\
\text { trabajo, con el propósito de incrementar la calidad del } \\
\text { capital humano y vincularlo estrechamente con el sector } \\
\text { productivo. }\end{array}$ & $\begin{array}{l}\text { Líneas de acción: } \\
\text { Incrementar los recursos del Fondo Sectorial } \\
\text { SEP-Conacyt, particularmente los dedicados a la } \\
\text { investigación científica básica. } \\
\text { Incrementar el número de becarios de posgrado en } \\
\text { ciencias o ingenierías. } \\
\text { Apoyar a los investigadores recién doctorados para } \\
\text { que logren su inserción laboral en las instituciones } \\
\text { generadoras de conocimiento del país. } \\
\text { Ampliar y fortalecer los programas para la inserción } \\
\text { laboral de personas con doctorado en la industria. }\end{array}$ \\
\hline
\end{tabular}

Fuente: elaboración propia a partir del PND y PSE 2013-2018.

De esta manera; el Conacyt tiene entre sus múltiples tareas, consolidar -junto a la Subsecretaría de Educación Superior de la Secretaría de Educación Pública (SEP) - un Programa Nacional de Posgrados de Calidad (PNPC) que busca "fomentar la mejora continua y el aseguramiento de la calidad de los posgrados nacionales, para incrementar las capacidades científicas, humanísticas, tecnológicas y de innovación del país" (Conacyt, 2014b, s.p.); en otras palabras, el PNPC se encarga de enlistar todos aquellos programas de posgrado mexicanos que cumplen con altos estándares de calidad educativa con la finalidad de que, en la medida en que los recursos presupuestarios de esta institución lo permitan, los estudiantes inscritos a éstos obtengan una beca mensual durante los ańos para los que se encuentra diseńado el programa, y que 
sirve como medio para asegurar que los discentes destinen de forma exclusiva el tiempo a sus estudios.

Hasta noviembre de 2016, el PNPC se conformaba por 2087 programas: 271 especialidades (13\%), 1190 maestrías (57\%) y 626 doctorados (30\%) (Conacyt, s.f.). En lo que respecta a los posgrados cuya línea específica es la formación en el campo educativo (Bourdieu, 1997), los programas registrados representan solamente $3.59 \%$ del padrón nacional, los cuales responden a la demanda académica de la siguiente manera: una especialidad, 53 maestrías y 21 doctorados (Conacyt, 2016). Sin embargo; para el caso de los estudios especializados en formación de investigadores educativos, la oferta disminuye considerablemente al grado de ocupar $0.67 \%$ del total nacional y $1.87 \%$ dentro del campo de la educación (gráfica 1).

\section{GRÁFICA 1. Contexto de la investigación educativa en México}

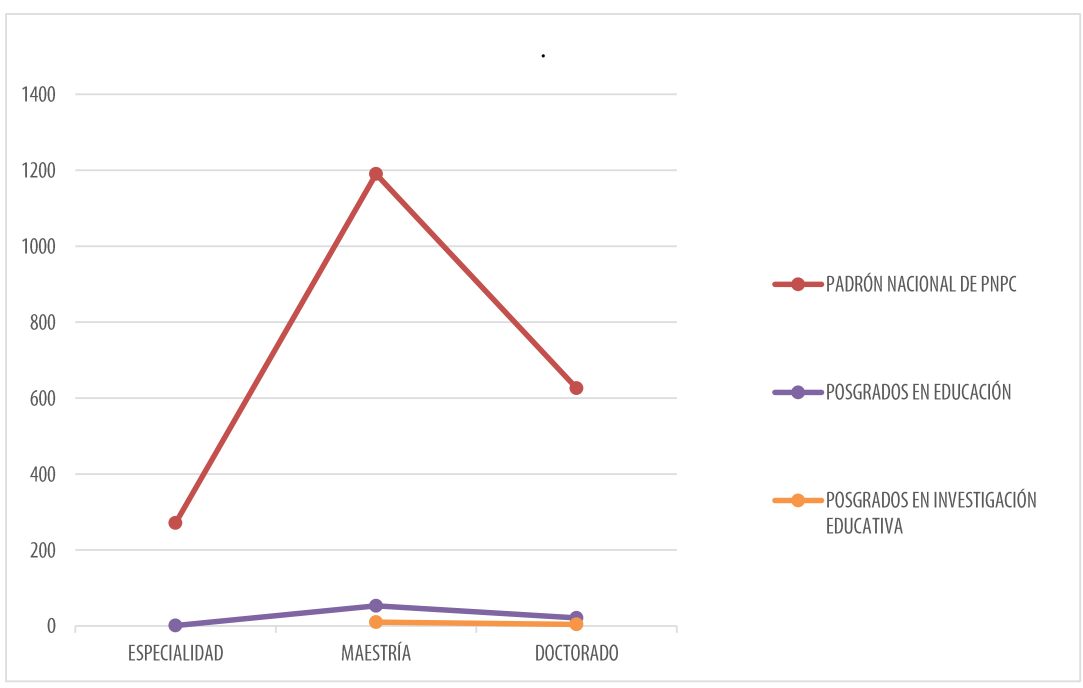

Fuente: elaboración propia a partir del Directorio PNPC 2016.

Con base en la gráfica anterior, se puede colegir que la investigación educativa es una de las áreas con menos presencia e incidencia dentro del campo de la formación de investigadores y en la producción de conocimiento científico en el país. Esta 
observación se sustenta en el hecho de que México cuenta solamente con diez maestrías y cuatro doctorados especializados para esta empresa, lo que obliga a reflexionar y a cuestionar la importancia -en términos de creación e incorporación de posgrados al PNPC- otorgada al campo de la educación a nivel nacional. En este sentido, son pocos los estados de la República que contribuyen al desarrollo de profesionales en el ámbito de la investigación educativa; éstos se ubican en la región Centro-Centro Norte del país que, a través de diez Instituciones de Educación Superior (IES), se encargan de desarrollar el 100\% del capital humano en esta área (imagen 1).

IMAGEN 1. Distribución de posgrados en investigación educativa en México

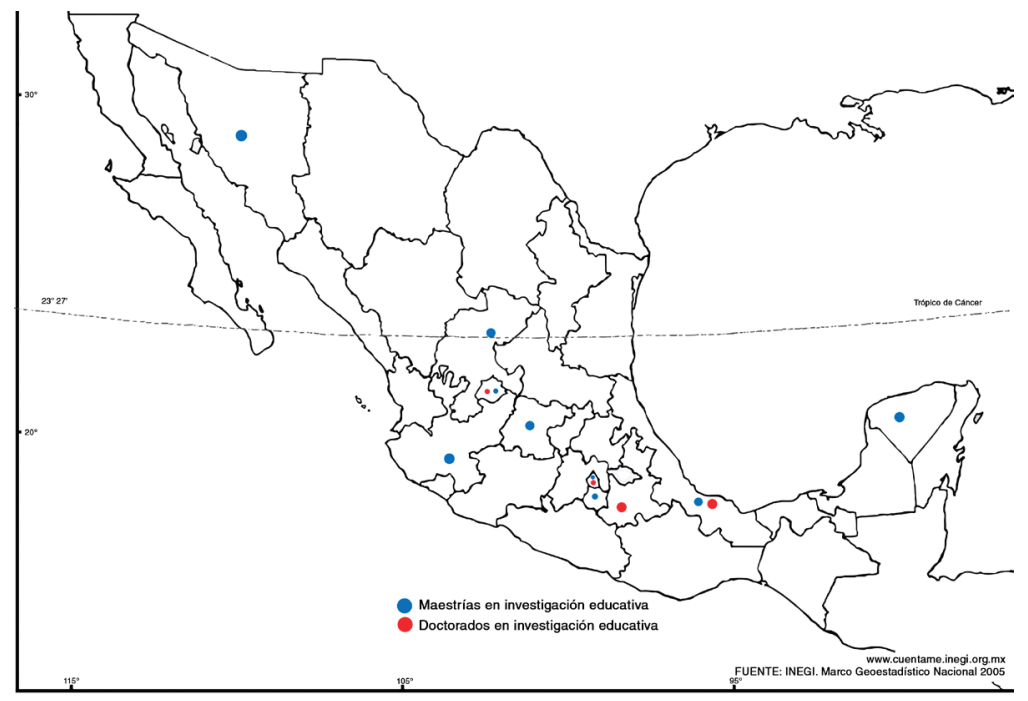

Fuente: elaboración propia a partir del Directorio PNPC, 2016. Imagen recuperada del INEGI.

De esta manera, IES como el Instituto Politécnico Nacional (Ciudad de México) y el Tecnológico de Sonora; las Universidades Autónomas de Aguascalientes, Yucatán, Zacatecas, Morelos, así como las Universidades de Guadalajara, Veracruz y de Guanajuato, son las encargadas de ofertar maestrías en el campo de la Investigacion Educativa. Por su parte, la Benemérita Uni- 
versidad Autónoma de Puebla, el Instituto Politécnico Nacional (Ciudad de México), la Universidad Veracruzana y la Autónoma de Aguascalientes están formando doctores en esta área. Con base en lo anterior, se constata que la situación por la que atraviesa el área educativa, en específico la relacionada con la formación de investigadores en este campo, es de notoria desventaja en relación con otras líneas de producción de conocimiento, condición que debe entenderse como un problema mayúsculo en términos de búsqueda de mejoras y soluciones a las problemáticas educativas nacionales en todos los niveles formativos.

Además del PNPC, el Conacyt vela por el desarrollo de conocimiento con alto rigor académico a través del SNI, el cual tiene por objetivo "[contribuir] a la formación y consolidación de investigadores con conocimientos... del más alto nivel como un elemento fundamental para incrementar la cultura, productividad, competitividad y bienestar social" (Conacyt, 2014c: s. p.). De esta manera, el SNI se consolida como el principal contenedor de investigadores activos a nivel nacional, lo cual es altamente probable que se deba -además del reconocimiento y prestigio otorgado por el Consejo- a los apoyos económicos a los que sus agremiados se hacen acreedores en el momento de su ingreso y permanencia en dicho sistema. Estos apoyos dinerarios están inmanentemente relacionados con el nivel alcanzado por sus ostentantes (Candidato, Nivel I, Nivel II, Nivel III y Emérito), remuneraciones que van de los tres hasta los 15 salarios mínimos por día (aunque existen excepciones para éstas); es decir, el SNI se convierte en un excelente apoyo para los investigadores en términos de estimularlos para la continuación de pesquisas y la producción de conocimiento científico y tecnológico en México.

Para enero de 2016, el SNI estaba conformado por 25077 miembros que desarrollan y producen conocimientos científico y tecnológico en las diversas áreas en las que el Conacyt distribuye sus intereses formativos y de investigación. En lo que respecta a la investigación educativa, se asevera que es de las áreas que menos científicos activos tiene en el campo (Bourdieu, 2000), ya que solamente cuenta con 617 investigadores que realizan pesquisas en las 19 líneas en las que éste se divide (Conacyt, 2014c), los cuales representan $2.46 \%$ del padrón total del SNI. Aunado al reducido 
número de especialistas y pese a las múltiples líneas de injerencia en el campo educativo, los intereses se posicionan sobre pocos objetos de estudio en la materia, lo que provoca el aumento de la ya tan asimétrica producción intelectual en México.

A través de los ańos, estos miembros del SNI (2.46\%) han consolidado algunas líneas dentro de la investigación en educación, como la matemática educativa y la formación y empleo de educadores, pero a su vez -inconsciente o conscientemente- se han debilitado otras de no menos importancia; tal es el caso de la calidad y gestión de la educación y, lamentablemente, la formación de investigadores educativos (ver gráfica 2), situación que sesga en gran medida el conocimiento al que se puede acceder en estas áreas dentro del campo.

\section{GRÁFICA 2. Número de investigadores por área de interés}

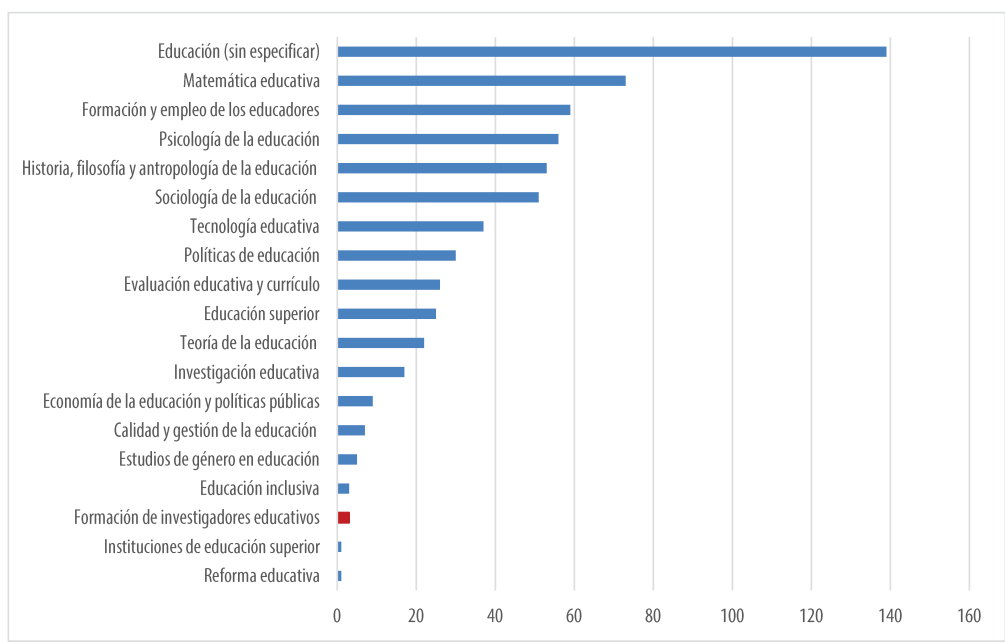

Fuente: elaboración propia a partir del Directorio SNI, 2016.

A partir de la gráfica 2 se impone la necesidad de cuestionar la trascendencia de algunas líneas de investigación dentro del campo educativo. En cuanto a la formación de investigadores educativos, ésta se erige como una de las líneas que mayor desinterés provoca en los miembros activos del SNI, situación que obliga a 
otear sobre este posible y fructífero objeto de estudio puesto que, a través del análisis y reflexión sobre la temática, se concibe la posibilidad de superar los escollos que el país presenta al respecto. Otra situación peculiar que se visualiza en términos de producción de conocimiento científico es la relación que guardan ciertas regiones de México para con la investigación en educación; es decir, la distribución de los investigadores se centra en áreas e IES específicas del país, por lo regular aquellas que gozan de reconocido prestigio a nivel nacional e internacional (ver imagen 2 ).

IMAGEN 2. Distribución de los investigadores educativos nacionales

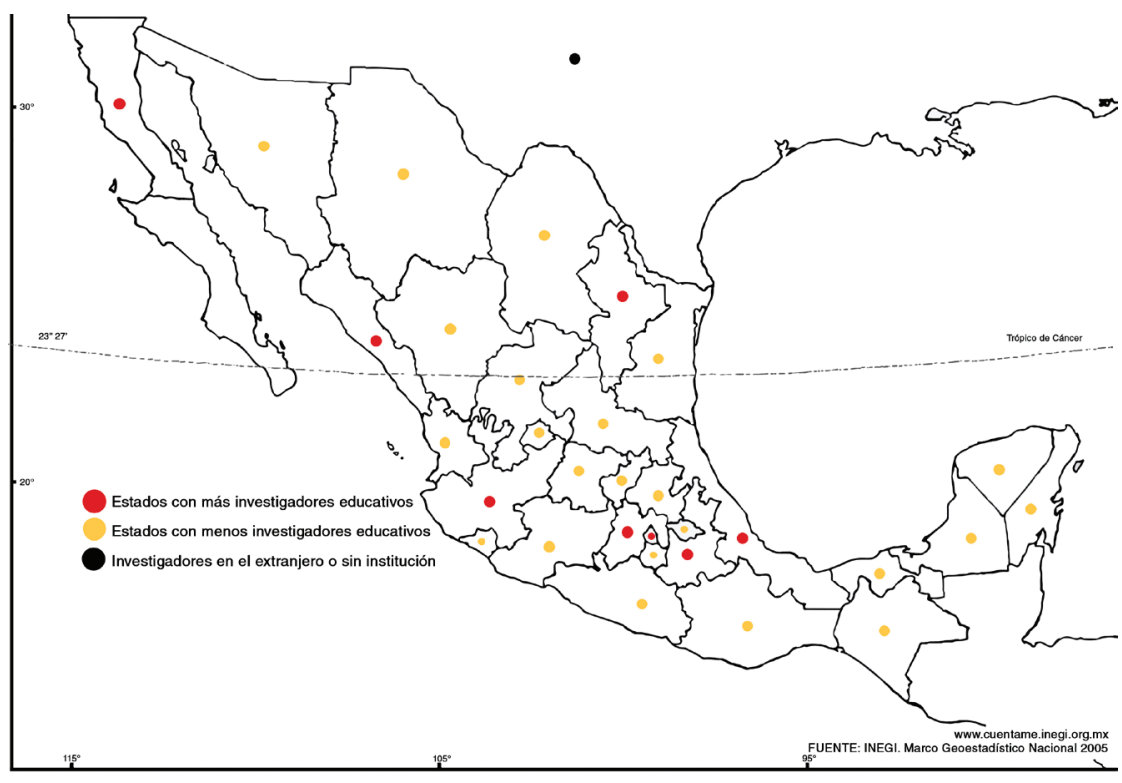

Fuente: elaboración propia a partir del Directorio SNI, 2016. Imagen recuperada del INEGI.

Con base en las imágenes 1 y 2 se comprueba que estados de la región Centro-Centro Occidente, como la Ciudad de México, a través de la Universidad Nacional Autónoma de México (UNAM), el Instituto Politécnico Nacional (IPN), el Colegio de México (COLMEX), entre otras; Puebla, con la Benemérita Universidad Autónoma de Puebla (BUAP), el Colegio de Pue- 
bla (COLPUE), etc., y Jalisco, con la Universidad de Guadalajara (UDG), el Centro de Investigaciones y Estudios Superiores en Antropología Social (CIESAS), Unidad Occidente, el Instituto Tecnológico y de Estudios Superiores de Occidente (ITESO) y otras más, son quienes más abonan en términos de producción científica y formación de investigadores en educación; por otro lado, la mayoría de los estados de la Región Sur-Sureste del país (Guerrero, Oaxaca, Chiapas, Tabasco y Campeche) son de los que menos contribuyen al campo educativo. De esta manera, cabe preguntarse, ¿cuál es la importancia que adquiere la investigación educativa, con especial énfasis en la formación de sus investigadores, para medrar los problemas nacionales por los que atraviesa este campo de conocimiento?

\section{BREVE ESTADO DEL ARTE SOBRE LA FORMACIÓN DE INVESTIGADORES EDUCATIVOS EN CHIAPAS}

116 La investigación educativa es una de las áreas del conocimiento científico que menos ha avanzado en los últimos años, bien sea por falta de interés de los potenciales investigadores (Rojas Soriano, 2008), bien por los deficientes recursos asignados a este campo de estudio o, peor aún, por la inmadurez de algunos agentes que conforman grupos de investigación en educación en los estados menos desarrollados; un claro ejemplo de esto lo es Chiapas (Morales Barrera, 2011). De esta manera, las pesquisas realizadas en el campo (Bourdieu, 1997) no son suficientes para dar respuesta a las necesidades y problemas por los que atraviesa la educación estatal y la nacional.

Con la intención de dar respuesta a la interrogante planteada; pero con el objetivo de exponer a fondo la realidad en torno a la relación Chiapas-investigación en educación, en este apartado se presentan las principales aportaciones de los trabajos realizados en el periodo 2003-2016, que tuvieron como objeto de estudio la formación de investigadores educativos en este estado. Con base en el análisis hecho por Leticia Pons Bonals y Juan Carlos Cabrera Fuentes (2013) -relacionado a la producción de conocimiento en el área "Procesos de formación" del Consejo Mexicano de Investigación Educativa (COMIE)-, se argumenta que durante 
el periodo 2003-2012 se produjo un artículo de revista y seis tesis en esta área; en consecuencia, se buscó ampliar dicho estado del arte a través de la recuperación de otros documentos -principalmente ponencias y ensayos- que tuvieron como eje central la misma línea temática. Producto de esta búsqueda, el apartado se enriquece con el análisis y reflexión de un artículo científico, un ensayo (2016) y tres ponencias, trabajos que permiten sustentar conclusiones sobre el tema, las cuales se enuncian a continuación.

La historia de la Formación de Investigadores Educativos (FIE) en el estado de Chiapas ha fijado una tendencia negativa que prevalece hasta la actualidad, puesto que pocas son las investigaciones realizadas sobre ésta, y la mayoría es producto de un mismo claustro de especialistas que conforman una comunidad epistémica (Alfaro Rivera, 2011), los cuales forman parte -sea como miembros o como colaboradores- de algunos de los cuerpos académicos de la UNACH o de las redes que estos cuerpos han tejido tanto a nivel nacional como internacional. En el cuadro 2 se exponen los principales hallazgos en la revisión de los documentos que cumplieron con las especificaciones mencionadas (que se encuentre en el periodo 2003-2016 y que tenga como objeto de estudio la FIE), principal sustento de las sucedientes reflexiones.

CUADRO 2. La investigación en la formación de investigadores educativos: el caso de Chiapas.

\begin{tabular}{|l|l|}
\hline \multicolumn{1}{|c|}{ Tipo de investigación } & \multicolumn{1}{c|}{ Principales aportes al campo de la FIE } \\
\hline $\begin{array}{l}\text { Artículo de investigación: } \\
\text { "La formación de investigadores } \\
\text { en educación: retos y perspectivas } \\
\text { para América Latina en el Siglo } \\
\text { XXI". } \\
\text { (Rincón Ramírez, 2004) }\end{array}$ & $\begin{array}{l}\text { La FIE debe constituirse desde la multi, inter y transdisciplinariedad, que dé } \\
\text { respuesta a las problemáticas del campo educativo en y desde este espacio. Por } \\
\text { ello, es necesario formar investigadores educativos integrales y polivalentes con } \\
\text { dominio en diversas áreas del conocimiento científico y bajo cuatro principios } \\
\text { formativos: pedagógicos, filosóficos, sociológicos y psicológicos. } \\
\text { Estas áreas deben estar direccionadas en todo momento, por el interés de } \\
\text { desarrollar habilidades y conocimientos teóricos y metodológicos en el } \\
\text { alumnado interesado en la FIE a través del trabajo colegiado de todos los } \\
\text { actores involucrados (docentes y estudiantes). }\end{array}$ \\
\hline $\begin{array}{l}\text { Ponencia: } \\
\text { "Formación de investigadores } \\
\text { educativos regionales". } \\
\text { (Pons Bonals y Cabrera Fuentes, } \\
\text { 2009) }\end{array}$ & $\begin{array}{l}\text { El Conacyt, a través del PNPC, busca reconocer a los posgrados orientados a } \\
\text { la investigación; empero, continúa creciendo la oferta académica orientada a } \\
\text { profesionalizar y no a formar investigadores. } \\
\text { La formación de investigadores obliga a la apropiación del habitus científico; es } \\
\text { decir, a plantearse prácticas reflexivas, creativas y articulatorias en un proceso } \\
\text { heurístico de formación. }\end{array}$ \\
\hline
\end{tabular}




\begin{tabular}{|c|c|}
\hline Tipo de investigación & Principales aportes al campo de la FIE \\
\hline $\begin{array}{l}\text { Ponencia: } \\
\text { "Interminables comienzos en } \\
\text { la formación del investigador } \\
\text { educativo en Chiapas". } \\
\text { (Castillo Castillo, 2009) }\end{array}$ & $\begin{array}{l}\text { Quienes deseen nombrarse investigadores educativos necesitan, además del } \\
\text { sistema de prácticas y quehaceres científicos, ser acreedores del reconocimiento } \\
\text { nacional dentro del campo; en otras palabras, deben ser miembros del SNI, del } \\
\text { COMIE, de preferencia de ambos y contar con apoyos para realizar investigación } \\
\text { educativa. } \\
\text { En la década de los noventa, la FIE pasaba por dos situaciones importantes: } \\
\text { 1) el docente universitario encontraba su primer acercamiento a la } \\
\text { investigación junto al inicio de su formación en el posgrado, y 2) a principios } \\
\text { de esta década, las opciones de formación eran casi nulas, lo que obligó a una } \\
\text { emigración docente hacia instituciones externas con formas de existencia } \\
\text { diferentes en el plano educativo. } \\
\text { Se concluye reflexionando el hecho de que, a pesar de contar en los últimos } \\
\text { años con posgrados formadores en investigación educativa, pocos de éstos } \\
\text { conocen el campo, lo que sugiere comprender que la FIE se está estancando en } \\
\text { el plano de lo discursivo. }\end{array}$ \\
\hline $\begin{array}{l}\text { Ponencia: } \\
\text { "Panorama de la investigación } \\
\text { educativa en Chiapas". } \\
\text { (Morales Barrera, 2011) }\end{array}$ & $\begin{array}{l}\text { Los } 65 \text { investigadores educativos en Chiapas están distribuidos en diferentes } \\
\text { Instituciones de Educación Superior (IES): } 53 \text { en la UNACH, cuatro en la } \\
\text { Universidad de Ciencias y Artes de Chiapas (UNICACH), tres en la Escuela } \\
\text { Normal Rural Mactumatzá, uno en la Universidad Intercultural de Chiapas } \\
\text { (UNICH) y dos en la Universidad Pedagógica Nacional (UPN) unidad 071. } \\
\text { Además de estas IES, el Colegio de la Frontera Sur (ECOSUR), Programa de } \\
\text { Investigaciones Multidisciplinarias sobre Mesoamérica y el Sureste (PROIMMSE) } \\
\text { de la UNAM y la Secretaría de Educación, también realizan investigación } \\
\text { educativa en el estado de Chiapas. } \\
\text { Un problema mayor en el estado, relacionado con la institucionalidad de la } \\
\text { investigación educativa, es que los intereses de investigación responden más } \\
\text { a intereses "no académicos", lo que lleva a la conformación de grupos y a una } \\
\text { jerarquización de los posibles y no posibles objetos de estudio. }\end{array}$ \\
\hline $\begin{array}{l}\text { Ensayo: } \\
\text { "La investigación educativa en las } \\
\text { Escuelas Normales de Chiapas: } \\
\text { entre pairos y derivas". } \\
\text { (Hernández Morgan, 2016) }\end{array}$ & $\begin{array}{l}\text { La Secretaría de Educación Pública (SEP), el Conacyt y el COMIE han abierto los } \\
\text { espacios para el desarrollo del campo de la investigación educativa; empero, se } \\
\text { observan deficiencias en la formación de investigadores, ya que la mayoría de } \\
\text { ellos tiene edades superiores a los } 50 \text { años y se visualizan las condiciones poco } \\
\text { favorables para la formación de nuevos cuadros. } \\
\text { Aunado a esto, el exiguo apoyo que se otorga al desarrollo investigativo en } \\
\text { educación hace que este campo de conocimiento se relegue en relación con } \\
\text { otras áreas, ya que los estándares de calidad nacionales e internacionales } \\
\text { sobre los que se evalúa la idoneidad de las pesquisas educativas terminan por } \\
\text { anquilosarlas. }\end{array}$ \\
\hline
\end{tabular}

Fuente: elaboración propia a partir del análisis de los trabajos citados.

A manera de recuento breve del estado de la cuestión (2003-2016) expuesto en el cuadro anterior, se puede afirmar que los trabajos responden a dos líneas específicas de investigación en el campo de la FIE; primero, se encuentran aquellos que se ubican en el eje que se nombrará "formación en el campo de la investigación educativa”, en los cuales se expresa la necesidad de formar investigadores que analicen, reflexionen e intervengan 
en los problemas por los que atraviesa la educación a nivel nacional y estatal; asimismo se exponen los avances -en términos del incremento del número de investigadores- que en este campo se ha logrado conseguir pero que, so pena de ello, no ha significado una mejora para la investigación educativa en entidades federativas como es el caso chiapaneco (Castillo Castillo, 2009 y Colina Escalante, 2011), ya que la producción continúa siendo exigua y el interés por centrar la FIE como objeto de estudio latente y necesario, todavía se visualiza muy lejano.

En la línea "posgrados formadores en investigación educativa”, se enuncian las principales instituciones -tanto públicas como centros de investigación- que han formado, y continuan haciéndolo, investigadores en el campo de la educación en esta entidad; tal es el caso de la UNACH, UPN y ECOSUR, por citar ejemplos, con la finalidad de evidenciar la producción científica que de estas instituciones ha surgido en forma de trabajos académicos. Dichas investigaciones concluyen que, a pesar de denotar una necesidad ingente en la formación de investigadores educativos, poco se ha realizado y avanzado al respecto (Rueda Beltrán, 2006), ya que muchos de los proyectos de posgrado, diseñados con la intención de coadyuvar en el desarrollo de la FIE, han quedado en el plano de los deseables en términos de objetivos y resultados.

Hoy día, el estado de Chiapas es un claro ejemplo de la gran demanda de investigación que representan las necesidades educacionales en la sociedad -en todos sus niveles formativos-, situación que ha obligado la apertura de la oferta educativa privada a gran escala, convirtiéndose, en los últimos ańos, en un macromercado lucrativo. A guisa de ejemplo específico, estudios realizados por la Alliance for International Higher Education Policy Studies (en Acuña Gamboa, 2013) demuestran que, para la sucesión de la década de los noventa, al inicio del nuevo milenio, las claves institucionales del sector privado se incrementaron en $342.5 \%$ y, por el contrario, se observó un detrimento considerable en las universidades públicas. Este aumento se debe, según Rodolfo Tuirán (2012), a una demanda cada vez más creciente por educación superior en el país, aspecto que busca, a corto plazo, la "universalización" de este nivel formativo de cara a la 
cobertura de 60\% para el ciclo 2021-2022, meta por demás esperanzada, propuesta por la Asociación Nacional de Universidades e Instituciones de Educación Superior (ANUIES), que no deja de ser tan ambiciosa como poco probable de alcanzar por las acciones y recursos que se necesitan para lograrlo.

Ante la acuciante proliferación de universidades particulares que ofertan posgrados en educación en Chiapas, y con sustento en el hecho de que, en el presente estado del arte no existen investigaciones que expongan y detallen -a través de un análisis comparativo- los procesos de FIE entre los sectores público y privado, surgió la necesidad de realizar el presente trabajo que tiene como meta abonar al campo de la investigación en FIE a través de las líneas de indagación, reflexión y acción que se aperturan como producto de estas pesquisas.

\section{LA FORMACIÓN DE INVESTIGADORES EDUCATIVOS EN EL ESTADO: PRINCIPALES HALLAZGOS}

México atraviesa por una serie de problemas en el desarrollo de Ciencia, Tecnología e Innovación (CTI), principalmente en aquellas áreas relacionadas con la producción de conocimiento científico y la formación de capital humano en posgrado. Ante tal situación; el Gobierno Federal y la SEP han aseverado en sus documentos rectores, que el desarrollo se dará en la medida que se alcance la inversión de 1\% del Producto Interno Bruto (PIB) que otros países destinan a este campo, ya que la inversión nacional no sobrepasa el 0.5\% (Gobierno de la República, 2013; SEP, 2013). De esta manera, en los estudios de posgrado "recae la responsabilidad de formar a quienes hagan una contribución directa para el avance del conocimiento, la innovación y el desarrollo científico y tecnológico" (SEP, 2013, p. 48), convirtiendo a este nivel educativo en la punta de lanza para el despegue del desarrollo en el país.

Para lograr este objetivo; se han diseñado líneas de acción específicas para estas áreas de intervención, entre las que destacan: 1) incrementar la inversión en CTI; 2) fortalecer los mecanismos, instrumentos y prácticas de evaluación y acreditación de la calidad de la educación superior tanto de los programas escolarizados 
como de los programas de educación mixta y no escolarizada; 3) revisar los regímenes de reconocimiento de estudios que imparten las instituciones particulares, a fin de otorgar validez oficial a dichas instituciones con base en criterios sólidos y uniformes de calidad académica, y 4) alentar la participación de estudiantes en el quehacer investigativo (Gobierno de la República, 2013; SEP, 2013). El estado de Chiapas no es ajeno a estas intenciones puesto que, al igual que el gobierno federal, pretende "fortalecer la investigación en las IES, en beneficio del desarrollo económico y social [a través de] la formación de recursos humanos de alto nivel científico, tecnológico y de innovación en el estado" (Gobierno de Chiapas, 2013, pp. 114 y 117). Con base en estas líneas de acción, se concibe que a través de la formación de investigadores se podrá dar respuesta a las problemáticas y necesidades por las que el país viene atravesando en áreas como economía, salud, desarrollo tecnológico, educación y política, entre otras.

La formación en el campo de la investigación conlleva, como lo asevera Rojas Soriano (2008, p. 155), "enfrentar un proceso complejo, cuyo carácter sociohistórico nos lleva a desafíos que rebasan con mucho los planteamientos tradicionalistas"; en otras palabras, formar o formarse como investigador en algún campo del conocimiento, obliga a docentes y estudiantes a desarrollar habilidades, competencias y destrezas propias del habitus científico (Colina Escalante y Osorio Madrid, 2004; De la Cruz Torres Frías, 2009; López Ordoñez y Naidorf, 2017). Por esta razón es necesario preguntarse, ¿cuáles son las características o cualidades que deben ostentar y desarrollar los interesados en formarse para la investigación?

La investigación se rige por objetivos, metas y visiones definidas desde su propia área de formación, lo que significa que el campo se ha consolidado a través de la historia en un habitus científico que todos lo estudiantes (principalmente) debían desarrollar. Definiendo el concepto de habitus como los "sistemas de disposiciones duraderas y transferibles ... predispuestas a funcionar como estructuras estructurantes ... como principios generadores y organizadores de prácticas y de representaciones" (Bourdieu, 2007, p. 86); o también, como el sistema de prácticas, preferencias, gustos y estilos de vida sobre los que se sustentan las 
formas de ser y hacer en un espacio social determinado, donde se accionan los capitales ostentados por los agentes que velan por su distinción. De esta manera, el habitus científico en México -en especial el de los investigadores educativos- entraña un meticuloso y estructurado conjunto de características y cualidades que lo diferencia en otros campos de conocimiento (ver cuadro 3).

CUADRO 3. Indicadores por áreas de formación dentro de la investigación educativa

\begin{tabular}{|c|c|}
\hline Áreas & Indicadores \\
\hline Actividades formativas & $\begin{array}{l}\text { Formación académica previa al Doctorado (Licenciatura, } \\
\text { Especialidad y Maestría). } \\
\text { Proyectos de investigación en los que funge como responsable y } \\
\text { organismo financiador. } \\
\text { Líneas de investigación en las que trabaja y ha trabajado. }\end{array}$ \\
\hline Conocimiento general en investigación educativa & $\begin{array}{l}\text { Planteamiento y dominio sólido de posturas teóricas y } \\
\text { epistemológicas para la investigación educativa. } \\
\text { Conocimiento y habilidad para emplear métodos, técnicas e } \\
\text { instrumentos de investigación en educación. } \\
\text { Capacidad para crear propuestas de intervención como objetivo } \\
\text { fundamental de todo proceso investigativo realizado. }\end{array}$ \\
\hline Reconocimiento científico e intelectual logrado & $\begin{array}{l}\text { Participación en Congresos nacionales o internacionales. } \\
\text { Artículos publicados (o por publicarse) en revistas con arbitraje } \\
\text { nacional e internacional. } \\
\text { Artículos periodísticos. } \\
\text { Reseñas. } \\
\text { Capítulos de libros. } \\
\text { Libros. } \\
\text { Investigaciones en proceso. } \\
\text { Pertenencia a comités editoriales, redes o cuerpos académicos } \\
\text { de investigación a nivel nacional e internacional. }\end{array}$ \\
\hline
\end{tabular}

Fuente: elaboración propia a partir de las investigaciones de Colina Escalante y Osorio Madrid (2004), así como de Jiménez Chaves y Duarte Masi (2013).

Con base en los indicadores anteriores, se logró analizar los procesos formativos en investigación educativa que las IES seleccionadas para este estudio ofertan a la sociedad chiapaneca. Previo a la exposición detallada de los resultados obtenidos durante las pesquisas; a manera introductoria, en el cuadro 4 se presenta la formación profesional de los participantes en el trabajo, el cual tiene como finalidad servir de antecedente para las sucedientes reflexiones. 


\section{CUADRO 4. Formación profesional de la muestra seleccionada}

\begin{tabular}{|c|c|c|c|c|}
\hline Formación previa al doctorado & UVG & US & IESCH & UNACH \\
\hline Licenciatura en Psicología Clínica & 4 & 1 & 0 & 0 \\
\hline Licenciatura en Pedagogía & 8 & 4 & 7 & 4 \\
\hline Licenciatura en Trabajo Social & 0 & 3 & 0 & 2 \\
\hline Licenciatura en Psicología Organizacional & 0 & 6 & 0 & 0 \\
\hline Licenciatura en Ciencias de la Educación & 3 & 0 & 4 & 0 \\
\hline Licenciatura en Enseñanza del Inglés & 0 & 0 & 2 & 0 \\
\hline Licenciatura en Educación Física y Deporte & 0 & 0 & 1 & 0 \\
\hline Licenciatura en Comunicación & 0 & 1 & 0 & 3 \\
\hline Licenciatura en Matemáticas & 0 & 0 & 1 & 4 \\
\hline Licenciatura en Intervención Educativa & 0 & 0 & 0 & 1 \\
\hline Licenciatura en Filosofía & 0 & 0 & 0 & 1 \\
\hline $\begin{array}{l}\text { Especialidad en Educación Media Superior con Enfoque } \\
\text { en Competencias Profesionales }\end{array}$ & 0 & 2 & 0 & 0 \\
\hline Especialidad en Formación de Formadores & 0 & 0 & 0 & 1 \\
\hline Especialidad en Didáctica de las Matemáticas & 0 & 0 & 0 & 2 \\
\hline $\begin{array}{l}\text { Especialidad en Procesos Culturales Lecto-Escritores } \\
\text { (PNPC-CONACYT) }\end{array}$ & 0 & 0 & 0 & 3 \\
\hline Maestría en Educación & 12 & 2 & 0 & 5 \\
\hline Maestría en Psicología Aplicada & 3 & 0 & 2 & 0 \\
\hline Maestría en Pedagogía & 0 & 7 & 3 & 0 \\
\hline $\begin{array}{l}\text { Maestría en Educación Básica con Enfoque en Estrategias } \\
\text { Didácticas }\end{array}$ & 0 & 6 & 0 & 0 \\
\hline Maestría en Educación Especial & 0 & 0 & 7 & 0 \\
\hline Maestría en Evaluación Educativa & 0 & 0 & 3 & 0 \\
\hline Maestría en Estudios Culturales (PNPC-CONACYT) & 0 & 0 & 0 & 6 \\
\hline Maestría en Docencia & 0 & 0 & 0 & 4 \\
\hline
\end{tabular}

Fuente: elaboración propia a partir de los resultados de la investigación.

Como se puede apreciar en el cuadro anterior, la diferenciada formación profesional de los participantes en el estudio enriqueció -a través de la heterogeneidad de las miradas y posturas disciplinares- los datos obtenidos durante la realización de las actividades. De esta manera, se presentan los hallazgos más relevantes de la investigación, los cuales permitieron reflexionar sobre la realidad por la que atraviesa el estado de Chiapas de cara a la FIE, situación que, como se hizo mención en apartados anteriores, merece una atención especial. 


\section{Formación de investigadores educativos desde el sector privado}

Las IES del sector privado han crecido considerablemente en los últimos años, al grado de representar casi $70 \%$ de la oferta educativa con la que cuenta el estado de Chiapas (Gobierno de Chiapas, 2013); esto es más evidente en el campo de la educación de la región Metropolitana. En lo concerniente a los posgrados formadores en investigación educativa, tanto la demanda como la propia oferta vienen marcando las pautas y abriendo las puertas para el nacimiento de más escuelas y la consolidación de las de mayor tiempo en el campo. Sin embargo, existen tres IES privadas en esta región (específicamente en la ciudad de Tuxtla Gutiérrez), que gozan de gran reconocimiento y pretigio dentro de la oferta educativa a nivel posgrado -por ser de las primeras en proponerlas en la entidad y por la gran cantidad de capital humano que año con año egresa de sus programas formativos-, lo cual las posiciona como las tres mejores instituciones en el estado, dichas instituciones son (no precisamente en orden de relevancia): Universidad Valle del Grijalva (UVG), Universidad del Sur (US) y el Instituto de Estudios Superiores de Chiapas (IESCH).

Dentro de los posgrados que estas IES ofertan, sobresale el Doctorado en Educación, el cual tiene como objetivo "formar doctores en Educación [capaces de] diseñar metodologías para el desarrollo de investigación educativa" (UVG, 2016, s.p.); "formar investigadores profesionales especializados en el campo educativo, con una base sólida en teorías educativas, epistemología, metodología, técnica, docencia y gestión educativa" (US, 2016, s.p.), y "formar Doctores en Educación que sean capaces de participar y emprender investigaciones científicas y tecnológicas" (IESCH, s.f., s.p.). Puesto que el objetivo primordial de los posgrados de estas IES es la formación de investigadores educativos, se indagaron los procesos - desde la mirada de los estudiantes y egresadossobre los cuales estos programas doctorales han desarrollado su capital humano, tomando como ejes de análisis las áreas de la FIE (ver cuadro 3). 


\section{Actividades formativas}

Esta área abre espacio para analizar las investigaciones que los 30 estudiantes y los 15 egresados (participantes que integran la muestra) de estos programas doctorales han realizado como producto de su quehacer investigativo. En específico, en este apartado se abordan los ejes "líneas de investigación" y "proyectos de investigación en el campo educativo", donde se obtuvieron datos tanto interesantes como preocupantes para la FIE (ver gráfica 3).

GRÁFICA 3. Actividades formativas en los Doctorados en Educación de las IES privadas

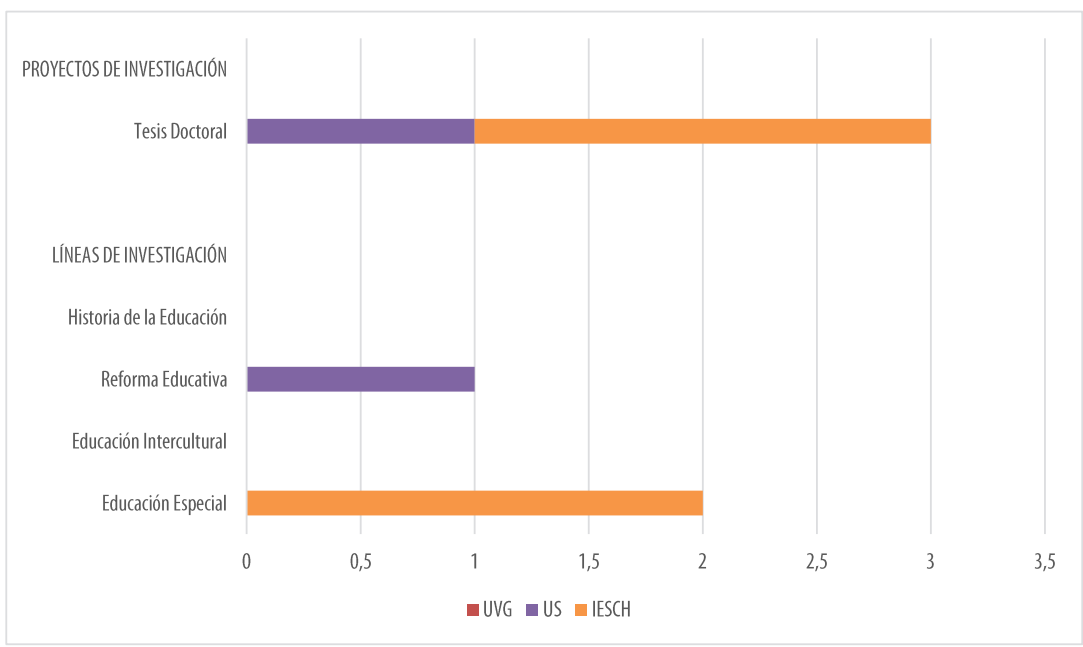

Fuente: elaboración propia a partir de los resultados de la investigación.

Como se puede apreciar en esta gráfica; las actividades formativas son muy limitadas en estos programas doctorales, ya que solamente $6.67 \%$ de la muestra se encuentra realizando proyectos de investigación en las líneas de educación especial (2) y reforma educativa (1), proyectos que responden al trabajo final para la obtención del grado (Tesis) que, expresado por los propios estudiantes, consideran remoto llevar a término por lo complicado que esta actividad les resulta; por otro lado, el resto de los participantes comentaron que han decidido obtener el grado con base en su desempeño académico durante el proceso formativo; esto 
se comprueba con lo comentado por algunos estudiantes y egresados de estas tres IES:

En el Doctorado nos piden que realicemos un proyecto de investigación para la tesis, pero en mi caso prefiero pasar las materias con buena calificación para que al final pueda titularme por mi promedio general (Estudiante IESCH).

Aunque nos piden que trabajemos un tema para la tesis del Doctorado, la verdad no le he puesto mucha atención ya que tengo un promedio general de 9.5, con lo cual puedo titularme por mis excelentes calificaciones, ya que lo mínimo es 9 (Estudiante UVG).

La verdad yo puedo titularme por mi promedio porque obtuve 9.9; lo malo es que no he podido titularme porque el trámite es demasiado costoso (Egresado US).

De esta manera se infiere que la formación en estas IES, en términos de actividades formativas, dista mucho de la necesidad de desarrollar competencias y habilidades para la consolidación del habitus científico en su población estudiantil, por lo que deja en tela de juicio los objetivos principales que rigen a estos programas doctorales, obligando el cuestionamiento de los verdaderos intereses en el sector educativo privado.

\section{Reconocimiento científico e intelectual logrado}

Parte importante de la FIE, por consiguiente del habitus científico, es el desarrollo de competencias y habilidades para presentar avances y resultados de las investigaciones que se realizan en el campo educativo. De esta manera, la participación en congresos y publicación de trabajos académicos a nivel nacional e internacional, así como la pertenencia a comités editoriales y redes o cuerpos de investigación son aspectos que deben forjarse durante los posgrados cuyo objetivo es la investigación. Por esta razón, resultó imprescindible analizar la realidad educativa -en términos de reconocimiento científico e intelectual logrado- en la que 
se están formando y fueron formados los participantes de las tres universidades privadas participantes (ver gráfica 4).

GRÁFICA 4. Reconocimiento científico e intelectual logrado

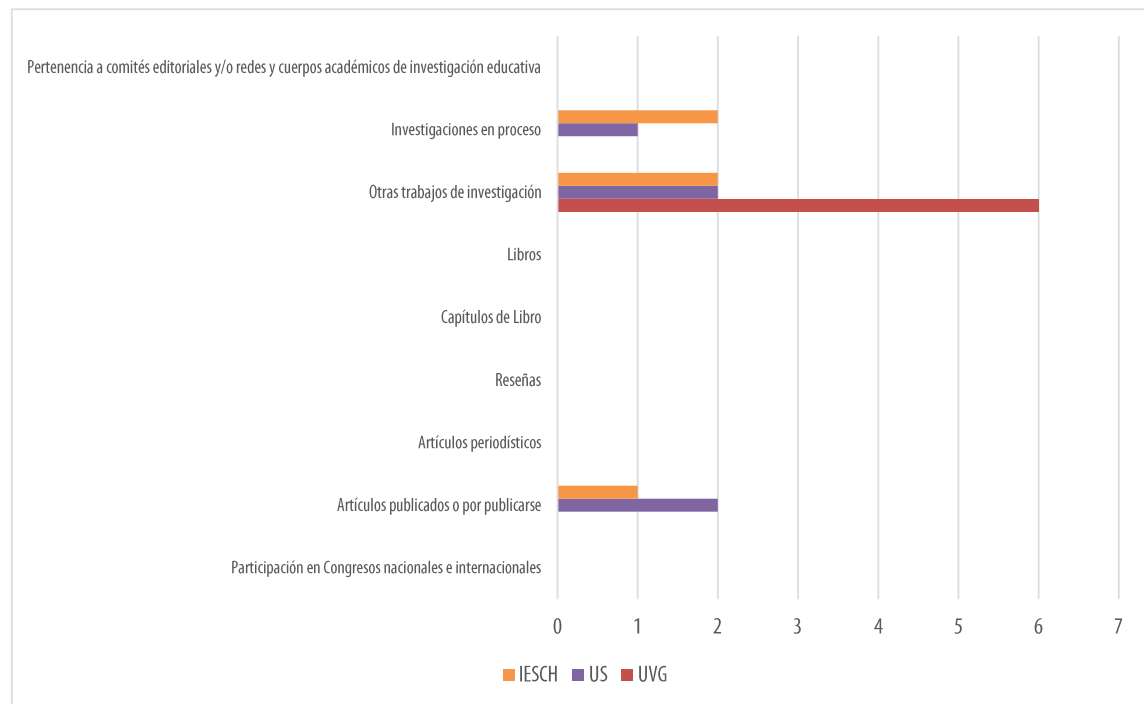

Fuente: elaboración propia a partir de los resultados de la investigación.

Son pocas las áreas en las que los participantes han desarrollado actividades científicas e intelectuales, teniendo como principal eje la realización de trabajos de investigación no publicables, como es el caso de las tesis de Licenciatura, que en total ascienden a 10 estudios (todos realizados en la UNACH). En lo concerniente a la publicación de artículos de investigación, solamente dos estudiantes de la US y un egresado del IESCH han logrado concretar este rubro en una misma revista científica no indexada de nombre Revista UNISUR, editada por la US, investigaciones que se relacionan con breves ensayos sobre temas educativos relevantes, como el caso de la inclusión educativa y la formación docente.

Las investigaciones en proceso responden, como se mencionó en el apartado anterior, a los proyectos de investigación doctoral de dos estudiantes de la US y uno del IESCH. Sin embargo; seis de los nueve indicadores en los que está conformada el área, de- 
muestran la gran carencia de producción y exposición científica con la que estos estudiantes y egresados han enfrentado su proceso formativo hacia la investigación educativa, carencias que generan escollos en el desarrollo de habilidades y competencias para adentrarse al campo en el que, en teoría, desean incidir. A decir de los participantes, estos aspectos formativos son ininteligibles para ellos, puesto que no son abordados en ningún momento dentro de sus respectivos programas doctorales, por lo que consideran que éstos no son necesarios para su preparación como investigadores; en sus palabras:

Es la primera vez que escucho el nombre de revista indiciada [sic] ... como se llame. En ninguna clase se nos hizo mención de este tipo de actividades, ni de participar en congresos; por eso creo que no son tan importantes en mi formación profesional como doctor (Estudiante UVG).

Nunca he participado en congresos ni en publicaciones de este tipo ... sin embargo, ahora que cuento con el grado de doctor, pienso que no necesito realizar este tipo de actividades, eso es para los que deciden hacer investigación solamente de escritorio (Egresado IESCH).

A manera de nota aclaratoria para los lectores, es necesario comentar que la información recabada en el área Conocimiento general en investigación educativa lleva a corroborar las carencias existentes en las dos anteriores, ya que el desconocimiento sobre la investigación educativa es tal, que resulta imposible exponerlo en gráficas o tablas, mucho menos a través de la presentación escrita. Con base en los datos expuestos conviene preguntarse, ¿a qué objetivo responde la oferta educativa privada de posgrados formadores en investigación en educación, si queda de manifiesto que éstos están muy lejos de desarrollar el capital humano que sus propios programas enuncian? y ¿quién o quiénes son los responsables de velar por la calidad educativa de estos posgrados? 


\section{Formación de investigadores educativos desde el sector público}

Como se ha mencionado en apartados anteriores, la educación pública superior ha venido decreciendo en los últimos años (Acuña Gamboa, 2013), bien sea por falta de asignación de presupuesto, bien por la rapidez con la que se expande la educación privada a nivel nacional. En el contexto chiapaneco la situación no es diferente, y más si se trata de la oferta académica en torno a la formación de investigadores en el campo educativo, puesto que la mayor parte de la población está siendo acaparada y formada por las IES de orden particular, desplazando a segundo término a las universidades públicas del Estado sin que esto signifique, en ningún momento, que la calidad de los servicios educativos privados sea mejor que la de los públicos.

Un ejemplo de esto se encuentra en la línea de investigación Educación, Actores y Procesos Enseñanza Aprendizaje (EAPEA) [ahora llamada Problemas Educativos Regionales], una de las cuatro academias en las que está conformado el Doctorado en Estudios Regionales (DER) de la UNACH, programa avalado por el PNPC del Conacyt. A pesar de que este programa doctoral no tiene como línea de formación específica la investigación educativa (por eso no aparece representada en la imagen 1), ya que por su carácter transdisciplinar, busca "formar investigadores ... en el campo de las ciencias sociales, el derecho y las humanidades, que atiendan los problemas en la macrorregión mesoamericana y las microrregiones de Chiapas" (UNACH, 2015, s.p.), se erige como una de las pocas IES públicas que desarrolla capital humano en el campo de la FIE.

Por esta razón, se consideró este programa doctoral como pieza fundamental para la confrontación de los procesos formativos -entre los sectores público y privado- que se desarrollan en el campo de la investigación educativa en Chiapas. A través de la muestra retomada para este estudio (diez estudiantes y cinco egresados), se obtuvieron datos importantes que se presentan a continuación. 


\section{Actividades formativas}

Las investigaciones realizadas en el DER han abordado diversas temáticas de relevancia regional, bien sea por lo contemporáneo de los temas, bien por la necesidad de explicaciones sobre realidades en demasía ignoradas u obviadas por las instancias gubernamentales. En el caso específico de la línea EAPEA, se observa cómo el quehacer investigativo de docentes y estudiantes ha impactado favorablemente en la entidad, puesto que la mayoría de las conclusiones y propuestas que han surgido de estos trabajos son el sustento para la intervención en los contextos desde donde se investigó. Lo anterior se constata en el gran interés por parte de quienes participan y continúan su consolidación en el campo de la investigación, sucediendo en varios casos, el mero trámite de la presentación de la tesis doctoral para la obtención del grado, la cual, a diferencia de las IES privadas, es de carácter obligatorio (ver gráfica 5).

GRÁFICA 5. Actividades formativas realizadas en la línea EAPEA del DER

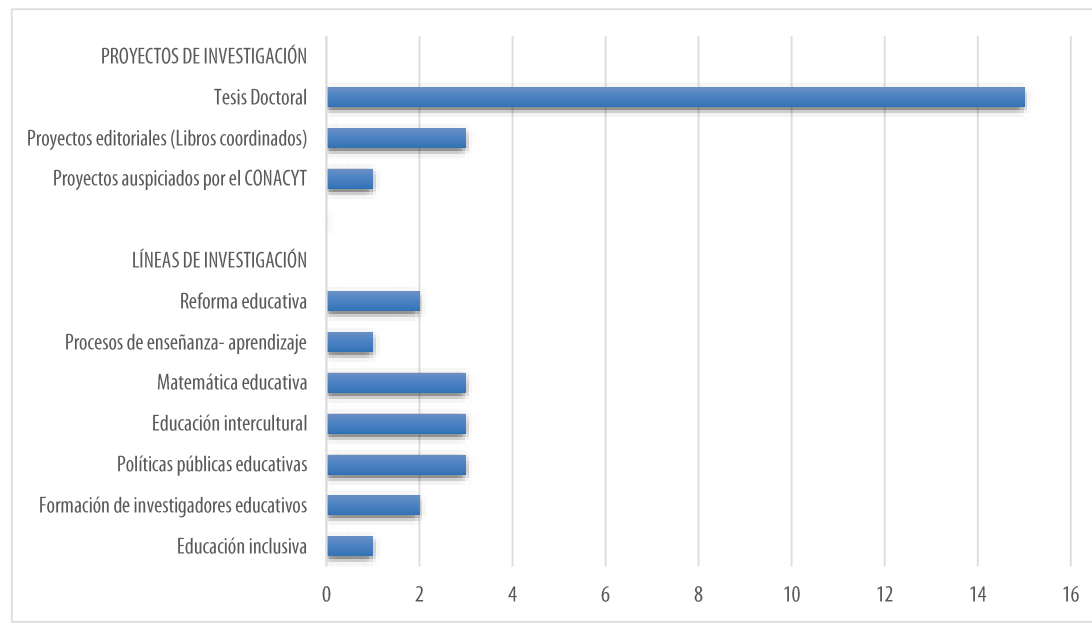

Fuente: elaboración propia a partir de los resultados de la investigación. 
Además del trabajo de tesis doctoral necesario para obtener el grado académico, los participantes comentaron que se encuentran trabajando en proyectos alternos de investigación. Por un lado, dos egresados y un estudiante del DER están coordinando libros -impresos y electrónicos- en el ámbito nacional e internacional sobre temáticas como la Matemática Educativa, la Formación de Investigadores y Políticas Educativas Comparadas; por otro, una egresada del mismo programa se encuentra colaborando en un proyecto avalado y auspiciado por el Conacyt sobre Equidad y Género. De esta manera se comprueba que, en términos de FIE, los estudiantes y egresados del DER están desarrollando las habilidades y competencias necesarias para la investigación, lo que ellos mismos mencionan:

Haber estudiado el Doctorado en Estudios Regionales resultó una experiencia formativa fascinante, a lo mejor no todos los compañeros piensen lo mismo, pero en verdad pienso que mi quehacer en investigación se lo debo al proceso y al diseño de este programa (Egresado UNACH).

Aunque no concluyo mis estudios doctorales, me siento con las herramientas suficientes para incidir en los contextos donde puedo desarrollarme como investigadora, ya que el DER me abre las puertas a múltiples opciones laborales (Estudiante UNACH).

\section{Conocimiento general en investigación educativa}

Otro de los elementos clave en la FIE son los aparatos teórico, epistemológico y metodológico que los investigadores emplean en sus estudios; por ello, fue necesario indagar sobre las principales tradiciones investigativas (Sandín Esteban, 2003) en las que se estructuran los trabajos en la línea EAPEA del DER, a fin de exponer las tendencias que prevalecen en este posgrado en términos de prácticas, preferencias y gustos que caracterizan el habitus científico (ver gráfica 6).

Como se puede comprobar; los estudiantes y egresados del DER, en la línea EAPEA, han adquirido conocimientos relevantes sobre investigación, los cuales han permitido asirse de herramientas teóricas, epistemológicas y epistemetodológicas (Tello, 2015) 
para sustentar sus trabajos investigativos, también para intervenir e incidir en los problemas educativos regionales a través de una lectura crítica de la realidad.

GRÁFICA 6. Conocimientos sobre investigación educativa en el DER

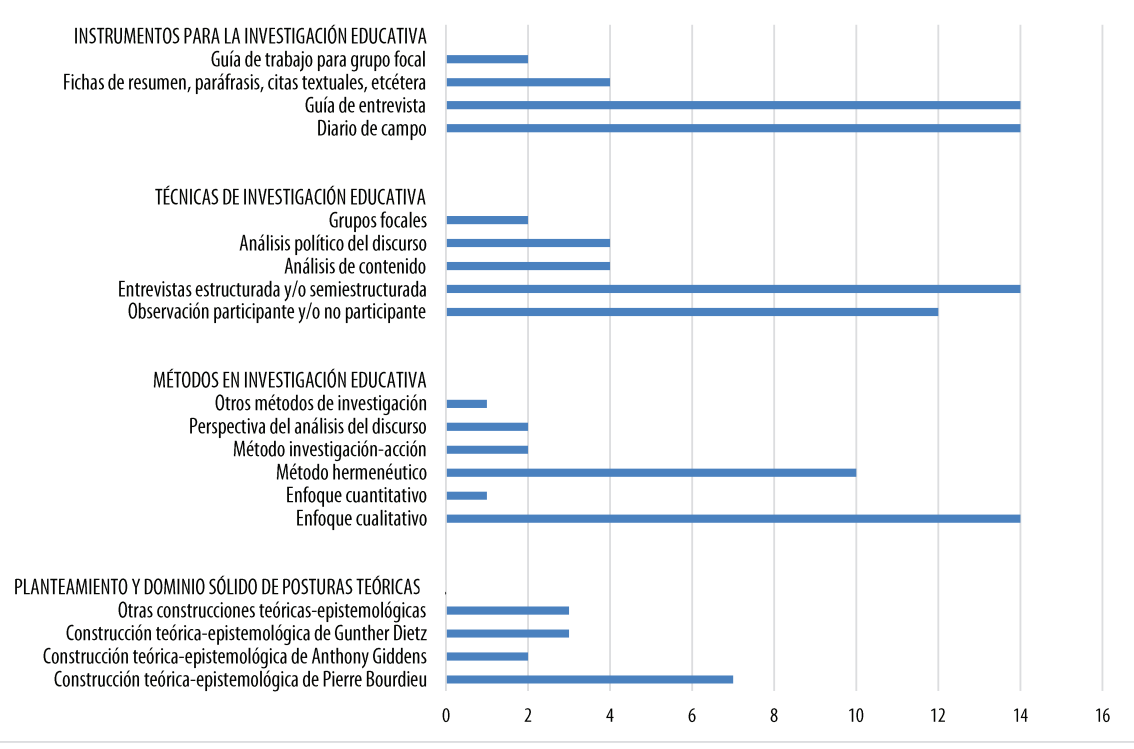

Fuente: elaboración propia a partir de los resultados de la investigación.

\section{Reconocimiento científico e intelectual logrado}

El habitus científico, en términos de FIE, se consolida en la medida que los investigadores en el campo van desarrollando habilidades, destrezas y competencias tanto para llevar a cabo pesquisas en un contexto y problema determinado, como para la publicación de sus resultados; por ende, el reconocimiento científico e intelectual -entendido en términos de publicación y exposición del trabajo académico- juega un papel fundamental al momento de estimar la relevancia que ha tenido un programa doctoral sobre sus estudiantes (activos y egresados), considerando esta área como el punto álgido en la formación investigativa. Con base en 
esto, se presentan los resultados obtenidos de las actividades realizadas con los participantes del sector público que acompañaron este trabajo de investigación (ver gráfica 7), resultados que abren la brecha, aún más, con los sistemas educativos privados.

GRÁFICA 7. Reconocimiento científico e intelectual en el DER

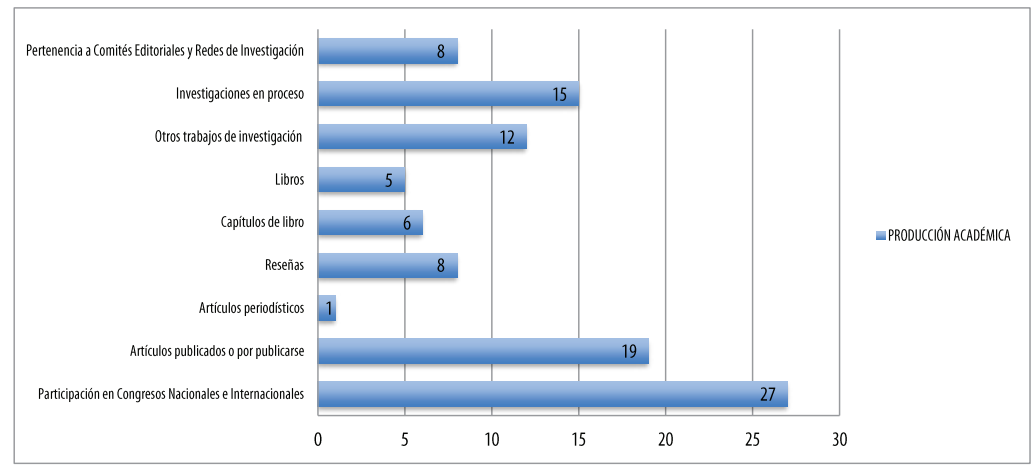

Fuente: elaboración propia a partir de los resultados de la investigación.

La participación como ponente en congresos, coloquios, foros y simposios; la publicación de artículos de investigación y reseñas críticas en revistas indexadas e indizadas, al igual que capítulos de libro en medios impresos y electrónicos, junto al trabajo de coordinación o compilación de libros en el ámbito nacional e internacional como objetivos impostergables para la obtención del grado de Doctor en Estudios Regionales, han hecho de este posgrado la mejor opción para la formación de investigadores en el campo educativo a nivel estatal. Esto se debe a que los lineamientos con los que rige el Conacyt obligan a los estudiantes a alcanzar el máximo desempeño durante sus estudios doctorales y, a los egresados, a la intervención en los diferentes ámbitos para los que desarrollaron habilidades y competencias, todo esto en aras de mejorar los problemas por los que atraviesan las regiones en las que son y hacen quehacer investigativo. 


\section{A GUISA DE CONCLUSIONES}

Chiapas es uno de los estados del país que obtiene los peores resultados en aprovechamiento escolar en los distintos niveles educativos, situación que hace de los estudios regionales una necesidad que permite comprender y proponer acciones en busca de mejoras y soluciones para esta realidad. Con base en los resultados obtenidos, se pueden abrir dos líneas de análisis y reflexión por las que se visualizan las conclusiones del trabajo: en lo específico, los procesos tan ambivalentes de FIE entre las IES del sector público y privado en Chiapas; en lo general, la calidad educativa de los posgrados avalados por el Conacyt y el desinterés gubernamental por consolidarlos, así como la dudosa y cuestionable calidad de la oferta educativa de las IES privadas y su acelerado crecimiento a nivel nacional.

La FIE entre el sector público y privado del estado de Chiapas presenta características tan opuestas, que imposibilitan hilvanar fines en común con los posgrados que ofertan a la sociedad. A pesar de que en el plano discursivo de ambos sectores se plasma el objetivo ex profeso de formar investigadores que incidan favorablemente en el campo educativo, todo apunta a que en las universidades particulares esta intención responde más a un spot atrayente que a una obligación ética por parte de los diseńadores y docentes que implementan dichos programas de estudio, por lo cual es necesario plantear nuevamente la pregunta ¿a qué objetivo responde la oferta educativa privada de posgrados formadores en investigación educativa, si queda de manifiesto que éstos están muy lejos de desarrollar el capital humano que sus propios programas enuncian?

Responder este cuestionamiento obliga a reflexionar, por lo menos, dos macro intereses que entran en juego principalmente dentro del campo de la educación superior: la mercantilización educativa y la descentralización de la educación. Por un lado, los estudios de posgrado se conciben hoy como el medio para abrir y mejorar las posibilidades laborales dentro de la gran sociedad meritocrática en la que se está convirtiendo el país, situación que no ha pasado desaperciba por los inversionistas, que ven en la demanda de formación un negocio lucrativo para sus finanzas 
desde inicios del nuevo milenio (Acuña Gamboa, 2013). Aunque lamentable, la educación superior ha devenido del campo de la investigación hacia el mercado de los posibles; en otras palabras, los sistemas universitarios privados en Chiapas están apostando por la educación, en la medida que los ingresos económicos generados a través de ella dan pauta para continuar con la inversión, puesto que la propia educación está sometida a los nuevos modelos y espacios económicos globales (Bauman, 2013).

Ante estos escenarios puede comprenderse que la FIE en los posgrados privados del estado de Chiapas, no busca la generación de capital humano de alto nivel (Gobierno de la República, 2013); más bien, se crea la realidad utópica donde los números (calificaciones) son la evidencia contundente de la buena formación pero, ¿por qué? La respuesta está inherentemente ligada con los elevados costos que significa la obtención del grado académico a través de esta modalidad: la intención es ganar más, no formar mejor.

Por otro lado, se posiciona a las autoridades gubernamentales y a su decimonónico, pero más cercano, deseo de descentralizar la educación superior. Si se parte de la reflexión anterior de que los intereses de los particulares son ganar más y no formar mejor, ¿por qué se otorgan cada vez más los permisos de Reconocimiento de Validez Oficial de Estudios (RVOE) a las IES privadas, cuando las visiones del PND y el PSE 2013-2018 argumentan la necesidad de controlar y evaluar dichos programas educativos para salvaguardar su calidad? En este sentido, es altamente probable que el incremento de la demanda educativa del sector joven del país está rebasando las posibilidades de atención de los distintos órdenes de gobierno, tanto en infraestructura escolar, como en presupuesto destinable para fines formativos, lo que ha obligado a la apertura del mercado escolar a los sectores privados para que den respuesta a la acuciante necesidad de formación después de la Licenciatura. Empero, en la medida que las IES privadas den cabida al mayor porcentaje de la población estudiantil a nivel posgrado -como es el caso chiapaneco-, las instancias gubernamentales podrán relegar, paulatinamente, su obligación al pecunio de la población y a la libre competencia de los particulares por ofrecer lo que más y mejor convenga; por ende, no es de relevante interés evaluar la 
calidad con la que estas instituciones forman a sus estudiantes, mucho menos las fuentes de empleo que éstos puedan obtener al concluir sus estudios doctorales. La búsqueda en la relación existente entre las IES privadas y públicas es la misma, las ganancias generadas a costa del perjuicio de la población. Aunque esto parezca tanto imposible como irrisorio, las acciones encaminadas de cara al 2030 en cuanto a la formación de investigadores desde el sector público, dan más elementos para reflexionar lo antes y ahora expuesto.

Aunque en el presente trabajo se demostró que la formación de investigadores educativos desde el sector público, específicamente en los programas avalados por el Conacyt, como el caso del Doctorado en Estudios Regionales, se erigen como el medio idóneo para el desarrollo del campo educativo en términos de producción de conocimiento, y a pesar que el discurso político pregona la oferta de una educación de calidad para todos, este objetivo se encuentra lejos del alcance y, cuando se habla de estos posgrados, el reto es tanto más titánico cuanto menos promisorio. Esto se comprueba en el hecho de que, en fechas recientes, el Conacyt ha sufrido constantes recortes presupuestales para su ejercicio, el más alarmante es el que oscila entre los 7500 y 8500 millones de pesos (Poy Solano, 2016a; Cruz, 2016; La Gaceta, 2016), el cual influirá en el decremento de $50 \%$ de apoyo a proyectos científicos (Poy Solano, 2016b). Aunque se niegue o trate de ocultar desde la cúpula gubernamental, también repercutirá en las becas de posgrado y en la movilidad para estudiantes, así como en el número de apoyos para estancias posdoctorales y los programas Cátedras Conacyt y Jóvenes Investigadores, que buscaban emplear a los recién egresados de los posgrados en el PNPC. Esta situación genera una rotunda contradicción entre lo deseable y lo realizable, ya que de nada sirven las visiones desarrollistas plasmadas en los documentos rectores nacionales, si en la realidad los intereses son tan opuestos como incongruentes, tan irracionales como dañinos.

Aunque el método no posibilita del todo la transferibilidad de los resultados (Álvarez Âlvarez y San Fabián Maroto, 2012), es altamente probable que lo ocurrido en Chiapas pueda estar sucediendo en otros estados de la República mexicana, principal- 
mente en aquéllos en los que se presentan índices muy bajos de producción de conocimiento en el campo de la Formación de Investigadores Educativos. En este sentido, este trabajo se visualiza como una invitación para posicionar la investigación educativa, específicamente la FIE, como objeto de estudio de los especialistas en el campo. En este documento se busca, más que facilitar respuestas exactas, suscitar el interés por tomar posturas críticas ante la realidad educativa en la que vivimos.

\section{REFERENCIAS BIBLIOGRÁFICAS}

Acuña Gamboa, L.A. (2013). La nueva cultura. Reflexiones en torno a la reconstrucción de la identidad del joven mexicano. Revista de estudios culturales y regionales Devenir, IV (25), 175-196.

Acuña Gamboa, L.A. y Pons Bonals, L. (2016). Calidad educativa en México. De las disposiciones internacionales a los remiendos del proyecto nacional. Revista Internacional de Investigación en Ciencias Sociales, 12(2), 155-174.

Alfaro Rivera, J.A. (2011). Conformación de comunidades epistémicas: Espacio para la formación de investigadores educativos. Ponencia presentada en el XI Congreso Nacional de Investigación Educativa, Nuevo León. Recuperado el 14 de marzo de 2016 de http://www.comie.org.mx/congreso/memoriaelectronica/v11/docs/area_11/0371.pdf

Álvarez Álvarez, C. y San Fabián Maroto, J.L. (2012). La elección del estudio de caso en investigación educativa. Gazeta de Antropología, 28(1), 1-12.

Bauman, Z. (2013). La globalización. Consecuencias humanas. Ciudad de México: Fondo de Cultura Económica.

Bonilla-Molina, L. (2016). Apagón pedagógico global. Las reformas educativas en clave de resistencias. Revista Viento Sur, (147), 92-101.

Bourdieu, P. (1997). Razones prácticas. Sobre la teoría de la acción. Barcelona: Anagrama.

Bourdieu, P. (2000). "Espacio social y poder simbólico". En P. Bourdieu, Cosas dichas (pp. 127-142). Barcelona: Gedisa. 
Bourdieu, P. (2007). El sentido práctico. Buenos Aires: Siglo XXI Editores.

Castillo Castillo, G. (2009). Interminables comienzos en la formación del investigador educativo en Chiapas. Ponencia presentada en el X Congreso Nacional de Investigación Educativa, Veracruz. Recuperado de http://www.comie. org.mx/congreso/memoriaelectronica/v10/pdf/area_tematica_11/ponencias/0799-F.pdf

Colectivo de actores clave en educación. (s. f.). Carta a la UNESCO sobre giro economicista de la educación. Recuperado de http://www.escuelasqueaprenden.org/imagesup/carta\%20a\%20la\%20unesco.pdf

Colina Escalante, A. (2011). El crecimiento del campo de la investigación educativa en México. Un análisis a través de sus agentes. Perfiles Educativos, XXXIII(132), 10-28.

Colina Escalante, A. y Osorio Madrid, R. (2004). Los agentes de la investigación educativa en México. Capitales y habitus. Ciudad de México: UNAM, CESU y Plaza y Valdés Editores.

Conacyt. (2014a). El Conacyt. Recuperado de http://conacyt. gob.mx/index.php/el-conacyt

Conacyt. (2014b). Programa Nacional de Posgrados de Calidad. ¿Qué es? Recuperado de http://conacyt.gob.mx/index. php/becas-y-posgrados/programa-nacional-de-posgrados-de-calidad

Conacyt. (2014c). Sistema Nacional de Investigadores. ¿Qué es? Recuperado de http://www.conacyt.gob.mx/index.php/ el-conacyt/sistema-nacional-de-investigadores

Conacyt. (2016). Programa Nacional de Posgrados de Calidad. Padrón de Programas 11/2016. Recuperado de http:// svrtmp.main.conacyt.mx/ConsultasPNPC/listar_padron. php

Conacyt. (s.f.). Sistema de Consultas. Introducción. Recuperado de http://svrtmp.main.conacyt.mx/ConsultasPNPC/ intro.php

Cruz, A. (2016). Científicos piden evitar el recorte de 23\% anunciado para Conacyt. Crónica. Recuperado de http://www. cronica.com.mx/notas/2016/985271.html 
De la Cruz Torres Frías, J. (2009). En busca de habitus científicos: la tutoría en un Doctorado en Educación. Ponencia presentada en el X Congreso Nacional de Investigación Educativa, Veracruz. Recuperado de http://www.comie. org. $\mathrm{mx} /$ congreso/memoriaelectronica/v10/pdf/area_tematica_11/ponencias/0197-F.pdf

Flick, U. (2012). Introducción a la investigación cualitativa. Madrid: Morata y Paideia.

Gobierno de Chiapas. (2013). Plan Estatal de Desarrollo Chiapas 2013-2018. Recuperado de http://chiapas.gob.mx/ plan-estatal

Gobierno de la República. (1989). Plan Nacional de Desarrollo 1989-1994. Recuperado de http://www.ordenjuridico. gob.mx/Publicaciones/CDs2011/CDPaneacionD/pdf/ PND\%201989-1994.pdf

Gobierno de la República. (1995). Plan Nacional de Desarrollo 1995-2000. Recuperado de http://www.zedillo.presidencia.gob.mx/pages/pnd.pdf

Gobierno de la República. (2001). Plan Nacional de Desarrollo 2001-2006. Recuperado de http://www.sagarpa.gob. $\mathrm{mx} /$ ganaderia/Publicaciones/List/Otros/Attachments/4/ PND0106.pdf

Gobierno de la República. (2007). Plan Nacional de Desarrollo 2007-2012. Recuperado de http://www.oic.sep.gob.mx/ portal3/doc/PMG/pnd_2007-2012.pdf

Gobierno de la República. (2013). Plan Nacional de Desarrollo 2013-2018. Recuperado de http://pnd.gob.mx/wp-content/uploads/2013/05/PND.pdf

Hernández Morgan, A. (2016). La investigación educativa en las Escuelas Normales de Chiapas; entre pairos y derivas. Recuperado de http://www.escuelanormallarrainzar.edu. $\mathrm{mx} /$ download/publicaciones_docentes/05_La-investigacion-educativa-en-las-Escuelas-Normales-en-Chiapasentre-pairos-y-derivas.pdf

IESCH. (s.f.). Educación. Recuperado de http://www.iesch.edu. $\mathrm{mx} /$ tuxtla/oferta-academica/doctorados/educacion/

Jiménez Chaves, V.E. (2012). El estudio de caso y su implementación en la investigación. Revista Internacional de Investigación en Ciencias Sociales, 8(1), 141-150. 
Jiménez Chaves, V.E. y Duarte Masi, S. (2013). Características del perfil de los investigadores categorizados por el Consejo Nacional de Ciencia y Tecnología del Paraguay. Revista Internacional de Investigación en Ciencias Sociales, 9(2), 221-234.

La Gaceta. Semanario de Sinaloa. (2016). Reducirán de 35 a 25 mmdp presupuesto de Conacyt: Carlos Karam. Recuperado de http://www.semanariolagaceta.com/scgi-bin/noticias.cgi?Action=Viewdetails $\& \mathrm{Pk}=12252$

López Ordońez, C. y Naidorf, J. (2017). La tutoría en Chiapas: el sentido de sus actores en la formación de investigadores. En L.A. Acuña Gamboa, A. Barraza Macías y A. Jaik Dipp, Formación de investigadores educativos en Latinoamérica: hacia la construcción de un estado del arte (pp. 133149). Victoria de Durango: ReDIE y Facultad de Filosofía, Letras y Ciencias de la Educación de la Universidad de Guayaquil.

140 Morales Barrera, M. C. (2011). Panoramas de la investigación educativa en Chiapas. Ponencia presentada en el XI Congreso Nacional de Investigación Educativa, Nuevo León. Recuperado de http://www.comie.org.mx/congreso/memoriaelectronica/v11/docs/area_11/0142.pdf

Peräkylä, A. (2015). Análisis de la conversación y el texto. En N. K. Denzin e Y. S. Lincoln, Métodos de recolección y análisis de datos (pp. 462-493). Barcelona: Gedisa.

Pons Bonals, L. y Cabrera Fuentes, J. C. (2009). Formación de investigadores educativos regionales. Ponencia presentada en el X Congreso Nacional de Investigación Educativa, Veracruz. Recuperado de http://www.comie.org.mx/congreso/memoriaelectronica/v10/pdf/area_tematica_11/ ponencias/0900-F.pdf

Pons Bonals, L. y Cabrera Fuentes, J. C. (2013). Avances sobre el estado del conocimiento de la investigación educativa en Chiapas, 2003-2012. Recuperado de https://ceieechis. wordpress.com/estado-del-conocimiento-2003-2012/

Poy Solano, L. (2016a). El titular de Conacyt pide a científicos sobrellevar el recorte. La Jornada. Recuperado de http:// www.jornada.unam.mx/2016/10/01/politica/008n1pol 
Poy Solano, L. (2016b). Reducirán más de 50\% a proyectos científicos: Conacyt. La Jornada. Recuperado el de http:// www.jornada.unam.mx/2016/10/12/politica/011n1pol

Rincón Ramírez, C. (2004). La formación de investigadores en educación: retos y perspectivas para América Latina en el siglo XXI. Revista Iberoamericana de Educación.

Rojas Soriano, R. (2008). Formación de investigadores educativos. Una propuesta de investigación. México: Plaza y Valdés S. A. de C.V.

Rueda Beltrán, M. (Coord.). (2006). Notas para una agenda de investigación educativa regional. Ciudad de México: COMIE/Fundación Ford.

Sandín Esteban, M. P. (2003). Investigación cualitativa en educación. Fundamentos y tradiciones. Madrid: Mc Graw Hill.

SEP. (2013). Programa Sectorial de Educación 2013-2018. Recuperado de http://www.sep.gob.mx/works/models/sep1/ Resource/4474/4/images/PROGRAMA_SECTORIAL_DE_ EDUCACION_2013_2018_WEB.pdf

Stake, R. E. (1999). Investigación con estudio de casos. Madrid: Morata.

Tello, C. (2015). Presentación. En búsqueda de la caracterización del campo teórico de la política educativa. En C. Tello, Los objetos de estudio de la politica educativa. Hacia una caracterización del campo teórico (pp. 13-21). Buenos Aires: Autores de Argentina.

Tuirán, R. (2012). La educación superior en México 2006-2012. Un balance inicial. Campus Milenio. Recuperado de http:// red-academica.net/observatorio-academico/2012/10/03/ la-educacion-superior-en-mexico-2006-2012-un-balance-inicial/

UNESCO. (2015). Declaración de Incheon. Educación 2030: Hacia una educación inclusiva y equitativa de calidad y un aprendizaje a lo largo de la vida para todos. Recuperado de http://unesdoc.unesco.org/images/0023/002331/233137s. pdf

UNACH. (2015). Doctorado en Estudios Regionales. Objetivos. Recuperado el 18 de julio de 2016 de http://www.der. 
doctorados.unach.mx/index.php/plan-de-estudios/objetivos

US. (2016). Doctorado en Educación. Recuperado de https:// www.universidaddelsur.edu.mx/doctorado/educacion. php

UVG. (2016). Doctorado en Educación. Recuperado de http:// www.uvg.edu.mx/oferta-educativa/doctorado-en-educacion/ 